\title{
Sosialisasi Penggunaan Kodefikasi (ICPC) di Puskesmas Kota Padang
}

\author{
Oktamianiza $^{1 \bowtie}$, Yulfa Yulia ${ }^{2}$, Deni Maisa Putra ${ }^{3}$, Niki Febriandari ${ }^{4}$, Zani Safitri ${ }^{5}$, Irvan Zafrant \\ Pratama $^{6}$, Tasya Nurul Huda ${ }^{7}$ \\ Rekam Medis dan Informasi Kesehatan, STIKES Dharma Landbouw Padang, Indonesia ${ }^{1,2,3,4,5,6,7}$ \\ E-mail : oktamianiza@gmail.com ${ }^{1}$, yulfayuliayy@gmail.com ${ }^{2}$, denimaisaputra@gmail.com ${ }^{3}$, \\ nikifebriandari@yahoo.co.id ${ }^{4}$, zanisafitri@gmail.com ${ }^{5}$, irvanzafrantpratama@gmail.com ${ }^{6}$, \\ tasyanurulhuda@yahoo.com ${ }^{7}$
}

\begin{abstract}
Abstrak
Pengodean merupakan salah satu kegiatan pengolahan data rekam medis untuk memberikan kode dengan huruf atau dengan angka atau kombinasi huruf dan angka yang mewakili komponen data. Pemberian kode ini merupakan kegiatan klasifikasi penyakit dan tindakan yang mengelompokan penyakit dan tindakan kriteria tertentu yang telah disepakati. Tujuan dari pengabdian kepada masyarakat ini untuk dapat tersosialisasinya penggunaan dari ICPC ini. Metode dengan FGD dan pemberian materi tentang penggunaan ICPC dan ICD-10 sebagai alat kodefikasi, yang digunakan pada sarana pelayanan kesehatan yang berbeda. Dalam hal ini untuk ICPC digunakan pada unit pelayanan kesehatan primer, seperti puskesmas dan dokter keluarga. Sedangkan ICD-10 dirancang untuk kodefikasi rumah sakit. Hasil kegiatan yang dilakukan secara umum untuk sosialisasi ini baik untuk pengenalan dan pengadaan alokasi waktu dalam menyampaikan materi berjalan dengan baik, lancar dan tetap pada sasaran yang dicapai. Jadi dalam pelaksanaan pengabdian masyarakat antara staf dosen, mahasiswa dengan petugas saling bekerjasama dengan sangat baik. Kegiatan pengabdian kepada masyarakat dapat diselenggarakan dengan baik dan berjalan dengan lancar sesuai dengan rencana yang telah disusun. Didapatkan adanya pemahaman petugas dalam pelaksanaan kodefikasi dengan menggunakan ICPC. Implementasi ICPC diharapkan segera di sosialisasikan oleh pemerintah. Motivasi petugas Puskesmas mendengarkan pemberian materi yang sangat baik dan memberikan kontribusi yang bagus untuk kelancaran pemaparan materi.
\end{abstract}

Kata kunci: kodefikasi, ICPC, ICD-10

\begin{abstract}
Coding is one of the medical record data processing activities to provide a code with letters or numbers or a combination of letters and numbers that represent data components. Giving this code is a disease classification activity and an action that groups diseases and certain agreed criteria actions. The purpose of this community service is to be able to socialize the use of this ICPC. Methods with FGDs and providing materials on the use of ICPC and ICD-10 as codification tools, which are used in different health care facilities. In this case, ICPC is used in primary health care units, such as puskesmas and family doctors. While the ICD-10 is designed for hospital codification. The results of the activities carried out In general, for this socialization, both for introduction and provision of time allocation in delivering the material went well, smoothly and remained on the achieved target. So in the implementation of community service between lecturer staff, students and officers work together very well. Community Service Activities can be carried out properly and run smoothly according to the plans that have been prepared. It was found that there was an understanding of officers in the implementation of the codeification using the ICPC. The implementation of the ICPC is expected to be immediately disseminated by the government. The motivation of the Puskesmas staff to listen to the presentation of the material was very good and made a good contribution to the smooth presentation of the material.
\end{abstract}

Keywords: codification, , ICPC, ICD-10

Copyright (c) 2021 Oktamianiza, Yulfa Yulia, Deni Maisa Putra, Niki Febriandari, Zani Safitri, Irvan Zafrant Pratama, Tasya Nurul Huda

$\triangle$ Corresponding author

Address : STIKES Dharma Landbouw Padang

Email : oktamianiza@gmail.com

ISSN 2721-9224 (Media Cetak)

DOI : https://doi.org/10.31004/abdidas.v2i3.330

ISSN 2721- 9216 (Media Online) 
685 Sosialisasi Penggunaan Kodefikasi (ICPC) di Puskesmas Kota Padang - Oktamianiza, Yulfa Yulia, Deni Maisa Putra, Niki Febriandari, Zani Safitri, Irvan Zafrant Pratama, Tasya Nurul Huda

DOI: https://doi.org/10.31004/abdidas.v2i3.330

\section{PENDAHULUAN}

Rumah sakit adalah institusi pelayanan kesehatan bagi masyarakat dengan karakteristik tersendiri yang dipengaruhi oleh perkembangan ilmu pengetahuan kesehatan, kemajuan teknologi, dan kehidupan sosial ekonomi masyarakat yang harus tetap mampu meningkatkan pelayanan yang lebih bermutu dan terjangkau oleh masyarakat agar terwujud derajat kesehatan yang setinggi-tingginya (Undang-undang Republik Indonesia, 2009).

Rekam medis adalah berkas yang berisikan catatan dan dokumen tentang identitas pasien, pemeriksaan fisik, pengobatan, tindakan dan pelayanan lain yang telah diberikan kepada pasien. Rekam medis harus dibuat secara tertulis, lengkap dan jelas atau secara elektronik, pencatatan rekam medis dimulai dari awal pasien datang berobat sampai pasien keluar dari rumah sakit dengan segala tindakan yang diberikan kepada pasien (PERMENKES RI No 269/MENKES/PER/III/2008, 2008). Setiap pencatatan kedalam rekam medis harus dibubuhi nama, waktu dan tanda tangan dokter, dokter gigi atau tenaga kesehatan tertentu yang memberikan pelayanan kesehatan secara langsung (Yasli, Leonard, \& Srimayarti, 2021).

Untuk melaksanakan pelayanan di rumah sakit diperlukan suatu bagian yang penting, yaitu rekam medis. Rumah sakit yang berkualitas, mampu menyajikan informasi yang lengkap tentang proses pelayanan medis dan kesehatan di rumah sakit tersebut. Oleh karena itu semua petugas di rumah sakit baik tenaga medis, pramedis, maupun tenaga non-medis harus menyelenggarakan pelayanan yang bermutu dan sesuai dengan standar yang telah ditetapkan melalui Keputusan Mentri Kesehatan No. 436/Menkes/VI/1993 (Sari \& Dewi, 2016).

Berdasarkan (PERMENKES RI No. 55 Tahun 2013, 2013) bahwa dalam melaksanakan pekerjaannya perekam medis mempunyai kewenangan sesuai dengan kualifikasi pendidikannya, salah satu kewenangan tersebut yaitu perekam medis melaksanakan sistem klasifikasi klinis dan kodefikasi penyakit yang berkaitan dengan kesehatan dan tindakan medis sesuai terminologi medis yang benar (Yasli et al., 2021).

Menurut (Pramono dkk, 2013), Coding merupakan pemberian penetapan kode dengan menggunakan huruf atau angka atau kombinasi huruf dalam angka yang mewakili komponen data. Pada ICD 10 ada penyebab kematian untuk mengetahui penyakit penyebab kematian secara nasional dan regional angka kematian kasar dan angka kematian menurut keompok umur (Oktamianiza, 2019).

Menurut (Rhahmawati \& Sudra, 2017) pemberian kode adalah pemberian penetapan kode dengan menggunakan huruf atau angka atau kombinasi huruf dan angka yang mewakili komponen data. Dalam pemberian kode, coder harus memperhatikan informasi penunjang seperti gejala, pengobatan serta tindakan medis yang mengarah ke pernyataan diagnosis dan prosedur yang kurang lengkap untuk menghasilkan informasi tambahan tentang diagnosis dan tindakan yang ditulis dokter sehingga dapat menghasilkan kode yang akurat. 
686 Sosialisasi Penggunaan Kodefikasi (ICPC) di Puskesmas Kota Padang - Oktamianiza, Yulfa Yulia, Deni Maisa Putra, Niki Febriandari, Zani Safitri, Irvan Zafrant Pratama, Tasya Nurul Huda DOI: https://doi.org/10.31004/abdidas.v2i3.330

Menurut Hatta (2012) pengkodean adalah prosedur pemberian kode dengan menggunakan huruf dan angka. Kegiatan pengkodean meliputi pengkodean diagnosa dan pengkodean tindakan medis. Hal penting yang harus diperhatikan oleh tenaga perekam medis adalah ketepatan dalam pemberian kode diagnosa. Pengkodean diagnosa yang tepat akan menghasilkan data yang akurat dan berkualitas. Ketepatan dalam pemberian dan penulisan kode berguna untuk memberikan asuhan keperawatan, penagihan biaya klaim, meningkatakan mutu pelayanan, membandingkan data morbiditas dan mortalitas, menyajikan 10 besar penyakit, serta hal-hal lain yang berkaitan dengan pelayanan kesehatan. Pengkodean diagnogsa yang tepat akan menghasilkan data yang akurat dan berkualitas (Devid Leonard, 2020).

Berdasarkan penelitian yang dilakukan oleh (Oktamianiza, 2016) bahwa kejelasan penulisan diagnosa utama tidak jelas sebanyak $29(29,0 \%)$, kelengkapan penulisan diagnosa utama tidak lengkap sebanyak 18 (18,0\%), ketepatan diagnosa utama tidak tepat sebanyak 24 (24,0\%), dan ketepatan kode diagnosa utama tidak tepat sebanyak 48 (48,0\%). Berdasarkan hasil penelitian tersebut dapat disimpulkan bahwa ketepatan pengodean diagnosa utama penyakit pasien masih kurang baik, maka peneliti menyarankan bahwa petugas koding harus aktif dan teliti dalam pengodean diagnosa utama pasien agar menghasilkan pelaporan yang baik sehingga mutu rumah sakit menjadi lebih baik kedepannya.

Berdasarkan permasalahan yang ada di puskesmas Kota Padang bahwa rata rata puskesmas belum menggunakan ICPC dalam melakukan pengodean, maka dari itu penulis ingin mengangkat kasus ini dan mengkajinya lebih dalam.

\section{METODE}

Tahap PKM diawali dengan penjajakan dan studi pendahuluan dalam rangka pengumpulan data, permohonan izin lahan, dan kesepakatan terkait MOU yang akan dibahas. Persiapan kegiatan PKM dalam bentuk pembekalan ilmu pengetahuan, dan praktek terhadap Sosialisasi Penggunaan Kodefikasi (ICPC) di puskesmas setelah mendapatkan izin dari Dinas Kesehatan Kota Padang dengan pelaksanaan PKM dilaksanakan selama 3 hari (10,11, 12 Juli 2019).

Persiapan PKM dilakukan dengan sering ilmu pengetahuan, cerah, dan diskusi selanjutnya melakukan simulasi penerapan penggunaan ICPC di puskesmas. Dalam pelaksanaan PKM jumlah peserta yang ikut ada 3 orang termasuk dengan pimpinan Puskesmas yang ikut andil dalam sosialisasi penggunaan ICPC. Evaluasi kegiatan melakukan terhadap pemanfaatan ICPC dengan menyebarkan angket kepada petugas.

\section{HASIL DAN PEMBAHASAN}

Kegiatan pengabmas dilaksanakan selama 3 hari berturut-turut dengan melibatkan 5 (lima) orang mahasiswa untuk membantu dalam pelaksanaan kegiatan. Tempat pelaksanaan di ruang pertemuan Aula Puskesmas dan lanjut ke ruangan rekam medis untuk sosialisasi penerapan kodefikasi ICPC di mulai dari jam 09.30-11.30 WIB untuk materi dan diskusi dan dilanjutkan simulasi penerapan SIMPUS dari jam 13.30-15.15 
687 Sosialisasi Penggunaan Kodefikasi (ICPC) di Puskesmas Kota Padang - Oktamianiza, Yulfa Yulia, Deni Maisa Putra, Niki Febriandari, Zani Safitri, Irvan Zafrant Pratama, Tasya Nurul Huda

DOI: https://doi.org/10.31004/abdidas.v2i3.330

WIB. Jumlah peserta yang menghadiri sebanyak 14 orang baik dari pihak kampus ataupun dari puskesmas.

\section{Khalayak Sasaran}

Khalayak sasarannya adalah petugas rekam medis yang akan memberikan laporan harian, bulanan, triwulan dan tahunan agar bisa terintegrasi kesemua lini pelayanan kesehatan yang berada di Puskesmas Kota Padang.

\section{Faktor Pendukung dan Penghambat}

1. Faktor Pendukung

a. Dukungan dari pihak Yayasan Pendidkan Dharma Landbouw padang dan Ketua STIKES dalam bentuk dukungan dan sumbang saran untuk kelancaran acara pengbdian masyarakat.

b. Tersediannya tenaga ahli dalam bidang pengetahuan untuk menerapkan sesuai dengan aplikasi ilmu pengetahuan yang didapat di pendidikan.

c. Dukungan dari Dinas Kesehatan Kota Padang.

d. Dukungan dai Kepala Puskesmas Kota Padang

e. Ketersediaan dana pendukung guna penyelenggaraan kegiatan pengabdian pada masyarakat.

2. Faktor Penghambat

Dalam pelaksanaan kegiatan pengabdian masyarakat tidak ada menemukan kendala apapun, dalam penyambutan oleh pihak Kepala Puskesmas sangat menerima kedatangan staf dosen ataupun mahasiswa/i STIKES Dharma landbouw Padang dengan tangan terbuka. Ini terbukti dalam kerjasama antara pihak Puskesmas dengan STIKES Dharma landbouw Padang. Akan tetapi perkiraan acara kegiatan aplikasi atau pengabdian masyarakat tertunda sedikit dikarenakan jaringan yang bermasalah, namun semua acara berjalan dengan lancar sampai waktu yang sudah ditetapkan. Kegiatan di ikuti oleh Kepala Puskesmas, pemegang program SIM-PUS sekaligus seluruh petugas rekam medis dan informasi kesehatan.

\section{Laporan Hasil Kegiatan}

Tujuan utama klasifikasi adalah pengumpulan data untuk tujuan penelitian dan penyunan kebijakan. Namun penggunan yang lebih luas dalam riset ditambahkan dengan penerapan dalam praktek serta munculnya konsep baru dalam kedokteran keluarga telah mendorong dikembangkannya kemanfaatan baru ICPC. Dari kegiatan yang dilakukan Adanya pemahaman petugas dalam pelaksanaan kodefikasi dengan menggunakan ICPC. Implementasi ICPC diharapkan segera di sosialisasikan oleh pemerintah.

Manfaat dari ICPC adalah untuk menggambarkan bentuk layanan pada setiap episode dan pencatatan komputer dari rekam medis pasien. Kedua fungsi itu sangat berhubungan, dan keduanya bergantungan pada 
688 Sosialisasi Penggunaan Kodefikasi (ICPC) di Puskesmas Kota Padang - Oktamianiza, Yulfa Yulia, Deni Maisa Putra, Niki Febriandari, Zani Safitri, Irvan Zafrant Pratama, Tasya Nurul Huda

DOI: https://doi.org/10.31004/abdidas.v2i3.330

data apa yang diinginkan dari pasien pada setiap kunjungan di praktek umum/DK dan pelayanan kesehatan primer.

Pelayanan kesehatan primer adalah pelayanan terpadu dan terjangkau oleh dokter yang bertanggung jawab memenuhi kebutuhan masyarakat luas akan pelayanan kesehatan, mengembangkan kemitraan yang langgeng dengan pasien dan berpraktek dalam konteks keluarga dan komunitas. Dalam satu episode pelayanan kesehatan pada sarana pelayanan primer, dimulai ketika suatu masalah kesehatan atau penyakit muncul pertama kali dalam kunjungan pasien ke provider sampai selesainya masalah tersebut pada kunjungan yang terakhir.

Alasan kunjungan merupakan inti dari satu episode layanan, dan ini dapat terdiri dari beberapa kali kunjungan termasuk berbagai perubahan layanan yang kemudian terjadi. Dengan demikian suatu episode layanan adalah semua layanan yang diberikan untuk suatu masalah kesehatan atau penyakit tertentu kepada seorang pasien. Kebutuhan akan layanan kesehatan perorangan yang utama, "comprehensiveness" tingkat keterpaduan, tingkat jangkauan dan kebertanggungjawaban dapat dinilai bila digunakan ICPC dalam rekam medis berkomputer.

Kode dalam ICPC-2 berasal dari struktur sumbu ganda sederhana yaitu 17 Bab (alfabetis) di satu sumbu dan 7 komponen (angka dua digit) di sumbu kedua. Nama bab ICPC menggunakan prinsip "jembatan keledai” (mnemonic) sehingga menudahkan dokter untuk menggunakannya sehari-hari walau dalam sistem pencatatan manual sekalipun. Klasifikasi ini tampil dalam bentuk daftra mulai dari komponen 1 sampai dengan komponen 7.

Rubrik untuk komponen 1 berisikan keluhan dan gejala, sedangkan rubrik di komponen 7 adalah diagnosis yang terdiri dari penyakit infeksi, neoplasma, cedera, cacat bawaan, dan lain-lain. Jadi kedua komponen ini spesifik untuk setiap bab. Sementara itu, rubrik pada komponen 2 sampai 6 adalah rubrik yang menggambarkan process of care sehingga seragam untuk semua bab dan sangat luas. Namun ICPC tidak menggambarkan temuan objektif dalam pemeriksaan fisik atau pemeriksaan laiinya. Setiap rubrik terdiri dari :

1) Kode tiga digit

2) Judul rubrik yang panjangnya terbatas

3) Kode ICD-10 padanannya

Klasifikasi kode ICPC, terdiri dari $17 \mathrm{Bab}$, dapat diuraikan sebagai berikut :

A : Umum dan Nonspesifik

B : Darah, organ pembentuk darah, organ linfatik (limpa, sumsum tulang.

D : Perencanaan

F : Mata

$\mathrm{H}$ :Telinga

K : Sirkulasi

L : Muskuloskletal

$\mathrm{N}$ : Neurologi

P : Psikologi

$\mathrm{R}$ : Pernafasan

S : Kulit

$\mathrm{T}$ : Endokrin, meatabolik dan nutrisi

$\mathrm{U}$ : Urologi

W : Kehamilan, kelahiran, kontrasepsi

$\mathrm{X}$ : Genitalia Perempuan (kromosom X)

Y : Genitalia Laki-laki (Kromosom Y) 
689 Sosialisasi Penggunaan Kodefikasi (ICPC) di Puskesmas Kota Padang - Oktamianiza, Yulfa Yulia, Deni Maisa Putra, Niki Febriandari, Zani Safitri, Irvan Zafrant Pratama, Tasya Nurul Huda

DOI: https://doi.org/10.31004/abdidas.v2i3.330

Z : Masalah Sosial

\section{Penerapan Klasifikasi dan Kodefikasi ICPC}

Pengguanaan ICPC dan ICD-10 sebagai alat kodefikasi, yang digunakan pada sarana pelayanan kesehatan yang berbeda. Dalam hal ini untuk ICPC digunakan pada unit pelayanan kesehtan primer, seperti puskesmas dan dokter keluarga. Sedangkan ICD-10 dirancang untuk kodefikasi rumah sakit. Adapun perbedaan ICPC-2 dan ICD-10, antara lain:

1) ICPC-2 :

- Format:

Menggunakan bab yang mengandung komponen

- Dasar klasifikasi:

Sistem tubuh (lokasi lebih utama dan etiologi) sehingga lebih rasional dan komprehensif;

- Bentuk:

Bukan nomenklatur sebab mencerminkan berbagai aspek dalam pelayanan kesehatan primer (tingkat pertama) dan distribusi;

2) ICD- 10 :

- Format :

Menggunakan bab (I-XXII);

- Dasar kualifikasi:

Sistem tubuh, dll (dicampur) sehingga 1 penyakit dapat masuk ke beberapa klasifikasi, contoh : influenza bisa masuk kedalam klasifikasi penyakit saluran napas dan infeksi;

- Bentuk:
Nomenklatur, sampai saat ini, klasifikasi terutama digunakan dalam pengumpulan data kepentingan statistik kesehatan dan menyusun kebijakan.

Kemajuan dalam rekam medis elektronik telah mendorong penggunaan yang lebih luas sebagai alat untuk menyimpan dan menata data yang terkumpulkan dari praktek sehari-hari. Semua data itu diperlukan baik sebagai bagian dari rekam medis pasien maupun sebagai sumber data untuk statistik kesehatan. Pengodean dan klasifikasi yang diperlukan untuk kedia tujuan itu berbeda dengan rekam medis pasien membutuhkan data spesifik serinci mungkin, sedangkan statistik kesehatan memerlukan data yang secara sistematis dikelompokkan ke dalam kelas berdasarkan kekerapannya atau kepentingannya ditinjau dari segi kebijakan. ICD-10 dikembangkan untuk tujuan yang terakhir.

\section{Aturan Penetapan Kode ICPC}

Untuk memberikan kode alasan kunjungan pasien, perlu ditetapkan dulu sistem organ yang sesuai atau babnya, pilih kode abjad yang tepat, kemudian pilih kode numerik 2 digit dari komponen yang sesuai sebagai gejala atau keluhan, diagnosis atau intervensi bab A digunakan untuk AKP yang berhubungan dengan sesuatu yang tidak spesifik atau menyangkut beberapa alasan organ.

1) Aturan 1

Alasan kunjungan pasien harus diberi kode yang setepat mungkin dan untuk itu mungkin saja diperlukan klarifikasi oleh penyedia. Contoh : Nyeri dada dapat dikode A11(“" 
690 Sosialisasi Penggunaan Kodefikasi (ICPC) di Puskesmas Kota Padang - Oktamianiza, Yulfa Yulia, Deni Maisa Putra, Niki Febriandari, Zani Safitri, Irvan Zafrant Pratama, Tasya Nurul Huda

DOI: https://doi.org/10.31004/abdidas.v2i3.330

Nyeri terasa diseluruh dada") atau K01 (“dada sakit karena jantung) atau R01 ("dada sakit karena batuk) atau L04 (“dada sakit setelah jatuh dari tangg). Keputusan untuk memilih bukan berdasarkan pendapat dokter, tetapi sebagaimana yang diungkapkan oleh pasien.

2) Aturan 2

Bila pasien mengemukan suatu pernyataan spesifik gunakan istilah yang digunakan. Contoh ikterus atau sakit kuning dalam bentuk istilah yang menyatakan diagnosis ditemukan dalam bab D (saluran cerna) yaitu D13, tetapi pasien mungkin mengemukannya sebagai kulit yang tampak kuning yaitu pada Bab S yaitu S08. Tak penting apakah pemberi layanan yakin yakni kelainan itu disebabkan oleh suatu hepatitis.

\section{3) Aturan 3}

Bila pasien tidak dapat menggambarkan keluhannya, maka alasan yang ditemukan oleh orang yang menemaninya dapat dianggap sebagai alasan yang dikeluarkan oleh pasien (misalnya seorang inu yang membawa anaknya atau kerabatnya yang mendampingi pasien yang tidak sadar).

4) Aturan 4

Semua masalah yang dikatakan pasien harus dicatat sebagai alasan kunjungan pasien, dan itu dapat lebih dari 1 (multiple coding). Contoh :" saya memerlukan obat hipertensi (K50). Selain itu payudara saya terasa kencang dan nyeri (X18). Bila kemudian pasien menyatakan ada benjolan dikulit, maka akan ditambah dengan kode S04.

\section{Aturan Memilih Kode Komponen}

Adapun ketentuan dalam memilih kode komponen dapat diuraikan sebagai berikut:

1) Gejala dan keluhan, alasan pasien mengunjungi pelayanan kesehatan paling sering dinyatakan dalam bentuk gejala dan keluhan, misalnya mual (D09), bersin (R07) dan lain-lain.

2) Prosedur diagnosis, penapisan dan pencegahan. Pada kenyataannya pasien dipelayanan primer dapat datang dengan alasan ingin mendapatkan tindakan tertentu, seperti imunisasi, memeriksakan darah, melakukan pemeriksaan prasali.

3) Terapi, tindakan dan pemberian obat Komponen ini digunakan ketika pasien memerlukan terapi tertentu atau ketika pasien diminta datang kembali oleh dokter untuk mendapatkan terapi, tindakan atau pengobatan. Misalnya : jika pasien memerlukan obat untuk infeksi sinus, maka akan dikode dengan R50.

4) Hasil pemeriksaan

Pada komponen ini digunakan bila pasien secara khusus mengatakan bahwa ia datang untuk mengambil hasil pemeriksaan yang telah dilakukan sebelumnya. Apabila hasil pemeriksaan tersebut negatif tidaklah mempengaruhi penggunaan komponen ini. Sering kali pasien ingin mendapatkan hasil pemeriksaan dan interpretasinya dan meminta informasi lebih lanjut tentang penyakit yang sebenarnya, maka perlu adanya kode tambahan -45 (penyuluhan kesehatan, nasehat). 
691 Sosialisasi Penggunaan Kodefikasi (ICPC) di Puskesmas Kota Padang - Oktamianiza, Yulfa Yulia, Deni Maisa Putra, Niki Febriandari, Zani Safitri, Irvan Zafrant Pratama, Tasya Nurul Huda

DOI: https://doi.org/10.31004/abdidas.v2i3.330

5) Masalah administrasi

Alasan kunjungan untuk keperluan adminstrasi pelayanan kesehatan, antara lain berupa pemeriksaan kesehatan yang dibutuhkan oleh pihak ketiga, misalnya asuransi.

6) Rujukan atau alasan untuk kunjungan

Jika alasan kunjungan pasien adalah untuk dirujuk ke penyedia layanan lainnya, maka komponen yang dipilih dapat -66, -67,-68. Bila pasien datang karena dikirim oleh dokter yang bersangkutan atau dikirim oleh dokter lain, maka kodenya -64 atau -65 .

\section{Diagnosis/Penyakit}

Komponen 7 hanya dipakai kalau pasien menyatakan nama suatu diagnosis penyakit sebagai alasannya. Pasien yang diketahuinya menderita DM tetapi datang dengan alasan lemah tidak diber kode DM, melainkan keluhan yang dinaytakan yaitu rasa lemah (A04) yang dikode, namun apabila dia datang untuk masalah DM-nya maka baru dikode dengan DM (T90).

\section{Aturan Pengodean dalam Memilih Komponen}

Aturan dalam pemilihan kode komponen dalam pengodean ICPC, sebagai berikut :

1) Aturan 1

Bila kode didahului oleh tanda sengkang pendek (-), artinya yang harus dipilih adalah kode abjad. Pilih kode A bila tidak ada bab khusus yang sesuai atau bila beberapa bab terlibat sekaligus. Kode yang lengkap adalah yang dimulai dengan kode abjad. Contoh : Biopsi dikode -52 , untuk sistem pencernaan menjadi D52, pemberian obat dikode dengan -50 untuk pemberian obat asma kodenya menjadi R50.

2) Aturan 2

Rubrik dari beberapa komponen, atau beberapa rubrik dari satu komponen dapat digunakan dalam satu kunjungan kalaupasien memang menyatakan lebih dari satu alasan kedatangan.

Contoh : Perut nyeri sejak tadi malam dan muntah beberapa kali, maka kode menjadi D01 dan D10;

Dengan adanya sosialisasi pengenalan ICPC ke petugas rekam medis membuat petugas rekam medis bisa memahami penggunaan dari ICPC tersebut.

\section{Evaluasi Kegiatan}

Secara umum penyuluhan pengabdian kepada masyarakat baik untuk pengenalan dan pengadaan alokasi waktu dalam menyampaikan materi berjalan dengan baik, lancar dan tetap pada sasaran yang dicapai. Jadi dalam pelaksanaan pengabdian masyarakat antara staf dosen, mahasiswa dengan petugas saling bekerjasama dengan sangat baik. Selain itu dalam mengemban tugas dan tanggung jawab tiap-tiap acara itupun juga berjalan dengan baik. Untuk tindak lanjut di kemudian harinya diharapkan pengabdian pada masyarakat hendaknya diprogramkan setiap tahunnya agar aplikasi ilmu pengetahuan tiap bidang ilmu pengetahuan yang diampu sangat bermanfaat bagi masyarakat yang membutuhkan, serta juga untuk menjalin keakraban dan silahturahmmi serta menjalin kerja sama yang erat 
692 Sosialisasi Penggunaan Kodefikasi (ICPC) di Puskesmas Kota Padang - Oktamianiza, Yulfa Yulia, Deni Maisa Putra, Niki Febriandari, Zani Safitri, Irvan Zafrant Pratama, Tasya Nurul Huda

DOI: https://doi.org/10.31004/abdidas.v2i3.330

antar masyarakat dengan pihak STIKES Dharma Landbouw Padang.

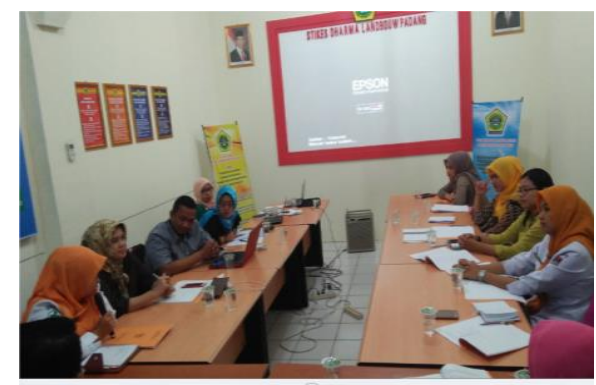

Gambar 1. Rapat Persiapan Kegiatan

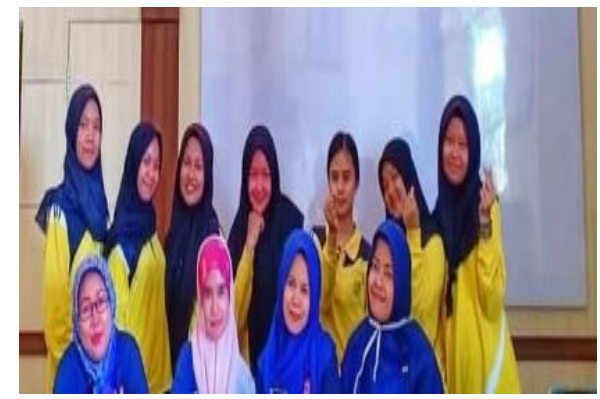

Gambar 2. Dokumentasi Tim Pengabdi dan Peserta Sosialisasi

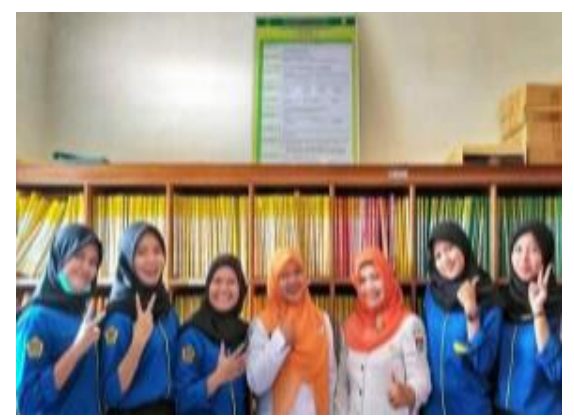

Gambar 3. Tim Pengabdi dan Peserta Sosialisasi di Bagian Rekam Medis

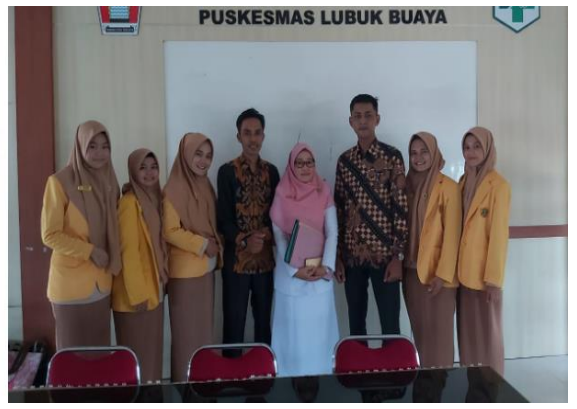

Gambar 4. Penutupan dengan Puskesmas

\section{SIMPULAN}

Kegiatan pengabdian kepada masyarakat dapat diselenggarakan dengan baik dan berjalan dengan lancar sesuai dengan rencana yang telah disusun. Motivasi petugas Puskesmas mendengarkan pemberian materi yang sangat baik dan memberikan kontribusi yang bagus untuk kelancaran pemaparan materi. Adanya pemahaman petugas dalam pelaksanaan kodefikasi dengan menggunakan ICPC. Implementasi ICPC diharapkan segera di sosialisasikan oleh pemerintah.

\section{DAFTAR PUSTAKA}

Devid Leonard, I. S. (2020). Penerapan Kegiatan Analisa Kuantitatif Rekam Medis Rawat Inap pada Ruang Marwa di RSI Siti Rahmah Padang. Administration \& Health Information of Journal, 1(1), 27-35. Retrieved from http://ojs.stikeslandbouw.ac.id/index.php/ahi /article/view/4/20

Oktamianiza. (2016). Ketepatan Pengodean Diagnosis Utama Penyakit pada Rekam Medis Pasien Rawat Inap JKN (Jaminan Kesehatan Nasional) di RSI Siti Rahmah Padang Tahun 2016. Penelitian Dan Kajian Menara Ilmu, 10(72), 159-167.

Oktamianiza. (2019). Mortalitas Coding. (D. S. Wilujeng, Ed.). Surabaya: CV DELTA AGUNG JAYA. 
693 Sosialisasi Penggunaan Kodefikasi (ICPC) di Puskesmas Kota Padang - Oktamianiza, Yulfa Yulia, Deni Maisa Putra, Niki Febriandari, Zani Safitri, Irvan Zafrant Pratama, Tasya Nurul Huda DOI: https://doi.org/10.31004/abdidas.v2i3.330

PERMENKES RI No 269/MENKES/PER/III/2008. (2008). permenkes ri 269/MENKES/PER/III/2008. Permenkes Ri No 269/Menkes/Per/Iii/2008.

PERMENKES RI No. 55 Tahun 2013, 2013. (2013). PERMENKES RI No. 55 Tahun 2013. Universidade Federal Do Triângulo Mineiro, 53(9), 1689-1699.

Pramono dkk, 2013. (2013). Keakuratan Kode Diagnosis Penyakit Berdasarkan Icd- 10 Di Puskesmas Gondokusuman Ii Kota Yogyakarta. Jurnal Manajemen Informasi Kesehatan Indonesia, 1(1), 42-61. https://doi.org/10.33560/.v1i1.58

Rhahmawati, I., \& Sudra, R. I. (2017). Keakuratan Kode Diagnosis Utama Diabetes Mellitus Tipe 2 Di Rumah Sakit Pku Muhammadiyah Karanganyar. Rekam Medis, 11(2), 129141.

Sari, T. P., \& Dewi, N. H. (2016). Keakuratan Kode Diagnosis Hepatitis Berdasarkan Icd10 Pasien Rawat Inap Di Rumah Sakit Lancang Kuning Pekanbaru. Jurnal Manajemen Informasi Kesehatan Indonesia, 4(1), 55-61. https://doi.org/10.33560/jmiki.v4i1.97

Undang-undang Republik Indonesia, N. $44 \mathrm{~T}$. 2009. (2009). UNDANG-UNDANG REPUNLIK INDONESIA NOMOR 44 TAHUN 2009. Aspectos Generales De La Planificación Tributaria En Venezuela, 2009(75), 31-47.

Yasli, D. Z., Leonard, D., \& Srimayarti, B. N. (2021). Analisis Kelengkapan Formulir A ( Evaluasi Awal MPP ) D an Formulir B ( Catatan Implementasi ) Pasien Rumah Sakit, $6(1), 31-41$. 